\title{
USING OF DICLAZURIL IN ATTENUATION OF EIMERIA SPECIES FOR INDUCTION OF PROTECTIVE IMMUNITY AGAINST COCCIDIOSIS IN LAYER CHICKS
}

\author{
SAHAR M. GADELHAQ ${ }^{1}$; WALID M. ARAFA ${ }^{2}$; AL HUSSIEN M. DAHSHAN ${ }^{3}$ and \\ SHAWKY M. ABOLHADID ${ }^{2}$ \\ ${ }^{1}$ Department of Parasitology, Faculty of Veterinary Medicine, Minia University, El-Minia, Egypt \\ ${ }^{2}$ Department of Parasitology, Faculty of Veterinary Medicine, Beni-Suef University, Beni-Suef 62511, Egypt \\ ${ }^{3}$ Poultry and Rabbit Diseases, Faculty of Veterinary Medicine, Beni-Suef University, Beni-Suef 62511, Egypt
}

Received: 13 September 2017; $\quad$ Accepted: 3 October 2017

\begin{abstract}
This study was conducted to evaluate the attenuating ability of diclazuril treatment on Eimeria species mix oocyst during and after sporulation for protection of layer chicks against Eimeria infection. Field isolates of Eimeria oocysts were collected and propagated in chickens to obtain a continuous source of oocysts. The collected un sporulated oocysts divided into two parts: the first part treated by diclazuril $20 \%$ during sporulation for $48 \mathrm{~h}$, while, the second part subjected for sporulation firstly, then treated by diclazuril $20 \%$ for $48 \mathrm{~h}$. The treated oocysts used in immunization of layer chicks at $4^{\text {th }}$ day of age. Chicks were divided into 6 groups: two groups inoculated by $20 \%$ diclazuril treated oocysts. The third group immunized by commercial live vaccine (Coccivac D) and fourth group inoculated by un treated oocyst. Two control groups (control infected un immunized group and control un infected un immunized group). At 21 day of age, chicks were challenged by $7.5 \times 10^{4}$ oocyst. The post immunization evaluation showed significant decrease in bloody diarrhea score, lesion score and oocyst shedding of diclazuril treated and commercial vaccine groups compared to the group inoculated by un treated oocyst. While the post challenge evaluation revealed a significant decrease in oocyst per gram (OPG) count, lesion value and bloody diarrhea score with improved weight gain in diclazuril treated groups compared to commercial vaccine group and control infected un immunized group. Also, diclazuril treatment showed excellent anticoccidial indices compared to commercial vaccine and un treated oocysts groups. The results of this study proved that diclazuril $20 \%$ concentration is effective in attenuation of Eimeria species oocyst and induced a significant protactive effect against challenge in layer chicks.
\end{abstract}

Key words: Diclazuril, Eimeria species, Immunity, Coccidiosis, Layer Chicks

\section{INTRODUCTION}

Coccidiosis is an important avian parasitic disease. It is caused by protozoan parasites of the genus Eimeria. Its infection leads to digestive disorders resulting from damage of the intestinal epithelia leading to mal-absorption of nutrients, reduced efficiency of feed conversion, and reduction in body weight gain. The global cost of coccidiosis in the poultry industry is estimated annually at more than US\$ 3 billion. It causes frequent mortality and economic losses, especially in outbreaks (Morris and Gasser, 2006). Prophylactic chemotherapy is still the main strategy of controlling coccidiosis, even though, Eimeria drug resistance still remains a tremendous obstacle, beside this E. tenella, E. acervuline and E.maxima are relatively tolerant to ionophores ( $\mathrm{Li}$ et al., 2004). Eimeria life cycle includes intracellular,

Corresponding author: Dr. WALID M. ARAFA

E-mail address: wmarafa@yahoo.com

Present address: Department of Parasitology, Faculty of Veterinary Medicine, Beni-Suef University, Beni-Suef 62511, Egypt extracellular, sexual and asexual stages. So immune responses to Eimeria are complex and contain many forms of nonspecific and specific immunity, the latter involving both cell mediated and humoral immune responses, the host immunity to avian coccidiosis is largely dependent on cell-mediated Immunity (Dalloul and Lillehoj, 2005).

Vaccination strategy is an effective, practical and an important alternative method for coccidiosis control (Conway and Mckenzie, 2007). The vaccination against coccidiosis is mainly based on the protective strong immune response and species-specific resistance that develops in chickens after oral administration of young chicks with a single or multiple doses of vaccine (Fetterer et al., 2014). Different types of vaccines are present like Live vaccines contain either attenuated or virulent coccidial strains and DNA recombinant subunit vaccines (Fetterer et al., 2014). Vaccination by wildtype parasites usually is successful but may cause disease due to un intended infections within a flock by ingestion of large numbers of oocysts by 
susceptible birds (Shirley and Bedrnfk, 1997). So, advances of vaccines based on novel, live attenuated populations of Eimeria species have been developed in the UK and the Czech Republic, like vaccines that contain 'precocious' lines of all seven species of Eimeria, oran egg-adapted line of E. tenella in combination with precocious lines of some of the other species (Shirley and Bedrnfk, 1997), even though, precocious strains production occur by isolation from virulent strains, by a robust method needing a large number of selections, and maintained by serial passage through native birds, thus increasing the cost of production (Fetterer et al., 2014). The main advantage of live attenuated vaccines have low reproductive potentials, so avoiding crowding in the specific mucosal areas of infection leading to the development of optimal immunity with minimal tissue damage (Allen and Fetterer, 2002).

Therefore, studying the attenuating effect of some anticoccidial drugs on the Eimeria sporozoites was carried out. Effect of toltrazuril on sporozoites of Eimeria tenella strains showed significant reduction the reproduction efficacy of $E$. tenella sporozoites (Thabet et al., 2015).

The aim of the current study was to evaluate the attenuating effect of diclazuril on Eimeria species oocysts to protect layer chicks against infection with multiple Eimeria species.

\section{MATERIALS AND METHODS}

\section{Parasite preparation}

Eimeria species oocysts (previously identified) were collected from a continuous source (experimentally infected chicks) in the lab. The oocysts were finally suspended in a shallow layer (5 mm deep) of in $2.5 \%$ potassium dichromate (K2Cr2O7) solution and are incubated at $28{ }^{\circ} \mathrm{C}$ temperature and $60-80 \%$ humidity for 60-72 $\mathrm{h}$ for sporulation (Reid and Long, 1979).

\section{Attenuation methods of unsporulated and sporulated oocysts}

\subsection{Attenuation by Diclazuril}

The common used anti coccidial drug Diclosol® $1 \%$ (Diclazuril $10 \mathrm{mg} / \mathrm{ml}$ ) was obtained from Pharma Swede Company for veterinary products. It was used by $20 \%$ concentrations from the stock. The diclazuril $20 \%$ was applied on unsporulated and sporulated oocysts $\left(5 \times 10^{5}\right.$ for each) that put in Petri dishes then incubated for $48 \mathrm{~h}$ at $25-29{ }^{\circ} \mathrm{C}$ and $80 \% \mathrm{RH}$. At the end of the incubation, the oocysts were washed thrice with phosphate buffered saline and stored at $4^{\circ} \mathrm{c}$ till used in immunization.

\section{Immunization and challenge protocol}

A total of 216 (1-day-old tetra layer chicks) industrial male layer chicks were purchased from (Cairo Co. Ltd.). The chicks were reared under standard management conditions at the laboratory of Parasitology Department, Faculty of Veterinary Medicine, Beni-Suef University, Egypt. All chicks were fed commercial withdrawal feed. Chicks were acclimated for 4 days before the initiation of the experimental procedures. At the $4^{\text {th }}$ day of age; chicks were randomly divided into 6 groups, each group has 36 chicks (12 chicks for each replicate for 3 ) and were reared at slatted wire cages, each replicate in a pen. Groups were; one group control negative (uninfected unimmunized), challenge group (infected un immunized) and other 4 immunized groups. Diclazuril treated Unsporulated oocysts group was immunized by $1 \times 10^{4} 20 \%$ diclazuril treated oocysts during sporulation. Diclazuril treated sporulated oocysts group was immunized by $1 \times 10^{4} 20 \%$ diclazuril treated oocysts after sporulation for $48 \mathrm{~h}$. Sporulated untreated oocyst group, was immunized by $1 \times 10^{4}$ sporulated untreated oocyst. Coccivac $D$ group was immunized by live commercial vaccine Coccivac $D$ (a living non attenuated vaccine containing all species of Eimeria and used for layers and breeders on feed 1000 oocyst / chick). The immunized groups were inoculated orally by the attenuated Eimeria species oocysts at the $4^{\text {th }}$ day of age by using of rubber stomach tube. Seven days post immunization, 3 chicks from each group were slaughtered to evaluate the attenuation efficacy by examination the intestinal and cecal lesions according to (Johnson and Reid, 1970) and oocyst count per gram feces.

At the $21^{\text {th }}$ day of age all chicks in the groups except the control negative one were challenged by $75 \times 10^{3}$ Eimeria species porulated oocyst mix.

\section{Evaluation of anticoccidial efficacy.}

\section{1. parasitological parameters and ACIs}

Post immunization and challenge experiment, chicks of each group were followed up for bloody diarrhea score (Dropping score) between day 4 and 7 post infection according to ( $\mathrm{Du}$ and $\mathrm{Hu}, 2004)$, graded (04 ) according to the consistency of the droppings and the presence of mucus and/or blood). Anti-coccidial index was calculated by using the formula as described by (Ma et al., 2011). ACI = (survival rate +relative rate of body weight gain) _ (lesion value+ oocyst value). An ACI > 180 indicated excellent activity, from 160 to 179 indicated moderate activity, from 120 to 159 indicated limited activity and $<120$ indicated inefficacy (Fei et el., 2013), whereas, survival rate was estimated by the number of surviving chickens divided by the number of total chickens. The chicks in all groups were scarified at the $28^{\text {th }}$ day of age (seven days post challenge) Wang et al. 2017 for lesion scoring according to (Johnson and Reid, 1970). Percent protection against lesions was also determined by using the formula described by (Singh and Gill, 1976), whereas, protection percentage against lesions $=($ Average lesion score of 
Infected unimmunized group - Average lesion score Infected immunized group/Average lesion score of Infected unimmunized group $x$ 100). Also, oocyst counting was done at the $7^{\text {th }}$ day post challenge. The fecal samples and cecal content were examined for presence of oocysts and counted by McMaster counting technique as mentioned previously. The oocyst value $=(\mathrm{OPG}$ in each treated group $) /(\mathrm{OPG}$ in group of infected untreated group) $\times 100$. Protection rate (in percent) was calculated as (OPG from infected untreated group - OPG from each treated group) / (OPG from infected untreated group) $\times 100 \%$ (Ma et al., 2011). Weight gain of the chicks in each group was determined by subtracting the body weight of the chicks at the time of challenge from the body weight at the end of the experiments (Pinard et al., 1998). The percentage increase in body weight gains (piBWG) was calculated as piBWG = (body weight after infection - body weight before infection) / (body weight before infection) $\times 100$. The relative ratio of body weight gains (rBWG) was calculated for each group according to the following equation: $\mathrm{rBWG}=$ (piBWGin each immunized group) / (piBWG in group of uninfected unimmunized group - piBWG in group of infected unimmunized group) $\times 100$ (Ma et al., 2011).

\section{Statistical analysis}

Data were analyzed statistically using Statistical Package for Social Science (SPSS for Windows (IBM), version 22, Chicago, USA) to determine if variables differed between treatments. Data were analyzed using ANOVA tests and subsequent Duncan's multiple range test to determine the differences between means. Results are expressed as means \pm SD. Probability values of less than $0.05(\mathrm{P}<$ $0.05)$ were considered significant.

\section{RESULTS}

Diclazuril $20 \%$ has very mild and non-significant inhibitory effect with mild oocyst wall deformities with $95 \%$ sporulation.

\section{1- Post immunization findings}

Monitoring of all immunized chicks from $4^{\text {th }}$ day post immunization (PM) revealed that diclazuril treated sporulated oocysts and commercial vaccine groups showed no blood in feces. While, diclazuril un sporulated oocysts group show mildly feces tinged with blood. In contrary, the chicks that inoculated with un treated oocysts show severe degree of bloody diarrhea. The results of lesion scoring PM of scarified three chicks from each group revealed that the commercial vaccine group showed no cecal or intestinal lesions. While diclazuril sporulated group showed mild lesion score. However, diclazuril un sporulated groups showed mild to moderate lesion score. Only one chick from three chicks, showed unilateral cecal content tinged with blood. On the other hand, the immunized by un treated oocyst group (control group for attenuation) showed bilaterally bloody cecal core.

The total OPG count PM appeared significantly lower in all immunized groups than the immunized by untreated oocysts group. While the OPG was significant lower in commercial vaccine group than other immunized groups. (Table 2) (Figure 1).

\section{Post challenge parameters}

\subsection{Parasitological parameters and gross lesion values}

Post challenge monitoring revealed that all infected chicks had variable clinical symptoms of coccidiosis. The most severe bloody diarrhea was observed in the infected unimmunized and commercial vaccine groups. While the other immunized groups showed no bloody feces, but low degree of diarrhea un tinged with blood (Table 1). Also the lesion scoring post challenge revealed no lesion in small intestine in all immunized and un immunized groups. While the cecal lesion scoring showed $100 \%$ severe lesions (3.0-4.0) in control unimmunized infected group. However, in diclazuril un sporulated group $30 \%$ of chicks showed no lesions and 70\% developed mild lesions (score 1). Meanwhile the diclazuril sporulated group $70 \%$ of chicks showed no lesions and 30\% developed mild lesion (score1). Also, Immunized un treated oocyst group $50 \%$ of chicks showed no lesions, meanwhile $40 \%$ showed mild lesions (score 1) and $10 \%$ developed severe lesion (score 3 ). On the other hand, the commercial vaccine group $90 \%$ of chicks developed sever lesions (score 3 \& 4), while $10 \%$ showed moderate lesions (score 2). Regarding the protection percentage against cecal lesions; showed that the highest protection percentage was in diclazurilsporulated group followed by diclazuril un sporulatedand Immunized un treated oocyst groups. The lowest protection was recorded in commercial vaccine group and the control unimmunized infected group. Furthermore, the mean caecal lesion score value was significantly lower in the two diclazuril treated and immunized by untreated oocyst groups than control infected un immunized and commercial vaccinegroups. (Table 2).

Moreover, the OPG count per gram feces in the $7^{\text {th }}$ day post challenge of diclazuril un sporulated, diclazurilsporulated and immunized by un treated oocysts groups was significantly lower than commercial vaccineand control infected un immunized groups (Table 2) (Figure 1). While the OPG count per gram of cecal content of diclazuril un sporulated, diclazuril sporulated and immunized by un treated oocyst groups was significant lower than the commercial vaccine and control infected un immunized groups. (Table 2) (Figure 2). Also all immunized groups showed lower than that of the control infected unimmunized and commercial vaccine groups (Table 2). 
The body weight post challenge, body weight gain and relative body weight gain were significantly higher in diclazurilun sporulated, diclazuril sporulated and immunized by un treated oocyst groups than the commercial vaccine and control infected un immunized group ( $p<0.05$ ) (Table 2$)$.

Table 1: Bloody diarrhea score post challenge in immunized and control groups.

\begin{tabular}{lcccc}
\hline $\begin{array}{l}\text { Day } \\
\text { Group }\end{array}$ & $\begin{array}{c}\mathbf{4}^{\text {th }} \text { day post } \\
\text { challenge }\end{array}$ & $\begin{array}{c}\mathbf{5}^{\text {th }} \text { day post } \\
\text { challenge }\end{array}$ & $\begin{array}{c}\mathbf{6}^{\text {th }} \text { day post } \\
\text { challenge }\end{array}$ & $\begin{array}{c}\mathbf{7}^{\text {th }} \text { day post } \\
\text { challenge }\end{array}$ \\
\hline Dicalzoruil Unsporulated & Score 0 & Score 0 & Score 0 & Score 0 \\
\hline Dicalzoruil sporulated & Score 0 & Score 0 & Score 0 & Score 0 \\
\hline Commercial vaccine & Score 0 & Score $3+++$ & Score $2++$ & Score $1+$ \\
\hline Immunized by un treated oocysts & Score 0 & Score 0 & Score 0 & Score 0 \\
\hline Control infected un immunized & Score 0 & Score $4++++$ & Score $3+++$ & Score $2++$ \\
\hline Control un infected un immunized & Score 0 & Score 0 & Score 0 & Score 0 \\
\hline
\end{tabular}

+ means $0-25 \%$ blood in the feces

++ means $50 \%$ blood in the feces

+++ means $75 \%$ blood in the feces

++++ means $100 \%$ blood in the feces

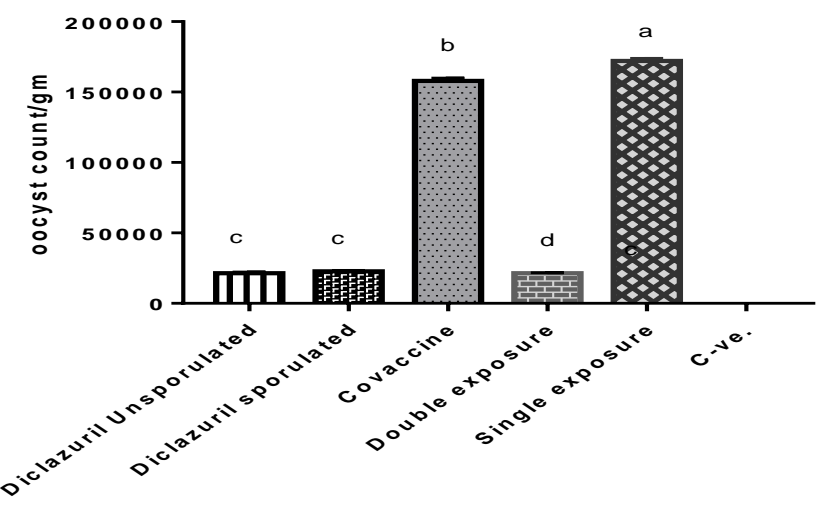

Group

Figure 1: The total OPG count on $7^{\text {th }}$ day post challange

a, b, c, d Means in the same column with different superscripts are significantly different $(p<0.05)$.

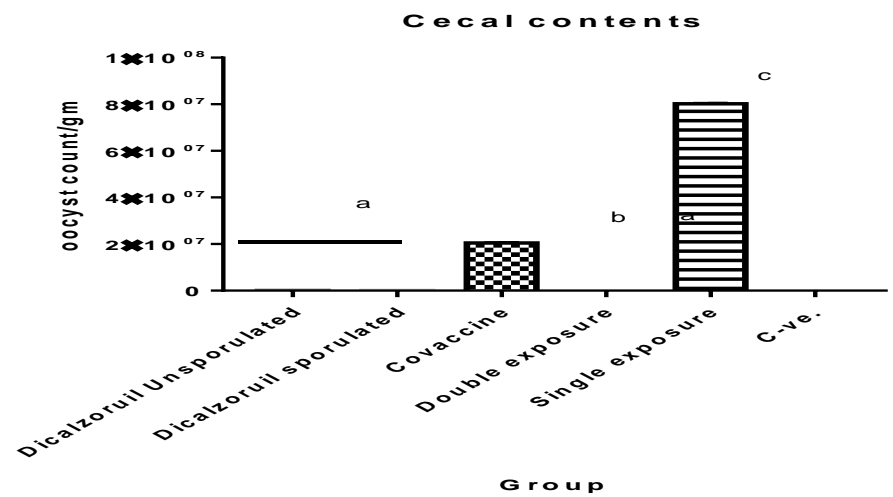

Figure 2: Cecal Oocyst count / gm feaces at $7^{\text {th }}$ day post challenge

a, b, c, d Means in the same column with different superscripts are significantly different $(p<0.05)$.

\subsubsection{Anti-coccidial indices (ACI)}

The calculated anticoccidial indices in all immunized groups were significant higher than that of commercial vaccine and control un immunized infected group. The ACIs were the highest indiclazuril sporulated group (198.37), followed by diclazuril un sporulated and immunized by untreated oocyst groups (185.53 and 178.9) respectively. The lowest ACIs were in the commercial vaccine group and control infected un immunized (65.89 and 16.43) respectively. Diclazuril sporulated and diclazuril un sporulated groups showed excellent anticoccidial efficacy (ACI >180), while immunized by untreated oocyst group showed moderate anticoccidial efficacy (ACI 160: 179). In the contrary commercial vaccine group showed anticoccidial inefficacy $(\mathrm{ACI}<120)$ (Table 2). 
Table 2: Post challenge evaluation parameters.

\begin{tabular}{|c|c|c|c|c|c|c|c|c|c|c|c|c|}
\hline Group & $\begin{array}{c}\text { Body } \\
\text { weight at } \\
\text { day of } \\
\text { challenge } \\
(\mathrm{g}) \\
\text { mean } \pm \mathrm{SD}\end{array}$ & $\begin{array}{c}\text { Body } \\
\text { weight at } \\
\text { day of } \\
\text { slaughter } \\
(\mathrm{g}) \\
\text { mean } \pm \mathrm{SD}\end{array}$ & $\begin{array}{l}\text { Body weight } \\
\text { gain at the } \\
\text { end of } \\
\text { experiment } \\
\text { (g) mean } \pm \\
\text { SD }\end{array}$ & $\begin{array}{c}\text { Relative } \\
\text { ratio of } \\
\text { body } \\
\text { weight } \\
\text { gain }\end{array}$ & SR & $\begin{array}{c}\text { Mean } \\
\text { lesion } \\
\text { score } \\
(\mathrm{M}+\mathrm{STD})\end{array}$ & $\begin{array}{c}\% \text { of } \\
\text { protection } \\
\text { against } \\
\text { lesion }\end{array}$ & $\begin{array}{c}\text { OPG in } \\
\text { feces at } \\
7^{\text {th }} \text { day PM } \\
(\mathrm{M}+\mathrm{STD})\end{array}$ & $\begin{array}{c}\text { OPG } \\
7^{\text {th }} \text { day PC } \\
(\mathrm{M}+\mathrm{STD})\end{array}$ & $\begin{array}{c}\text { Cecal } \\
\text { eocyst } \\
\text { count } \\
\text { (M+STD) }\end{array}$ & $\begin{array}{l}\text { Qocy } \\
\text { st } \\
\text { value }\end{array}$ & $\begin{array}{c}\mathrm{ACI} \\
(\mathrm{M}+\mathrm{ST} \\
\mathrm{D})\end{array}$ \\
\hline $\begin{array}{l}\text { Dicalzoruil } \\
\text { Unsporulatd }\end{array}$ & $\begin{array}{c}275.4 \\
\pm 13.23\end{array}$ & $\begin{array}{c}403.9^{c} \pm \\
21.89\end{array}$ & $\begin{aligned} & 128.5^{c} \\
\pm & 9.082951\end{aligned}$ & 99.04 & 100 & $\begin{array}{l}0.7^{b} \\
\pm 0.47\end{array}$ & $81.58 \%$ & $\begin{array}{c}0.835^{c} \mathrm{x} \\
10^{4} \\
\pm 100\end{array}$ & $\begin{array}{c}2.1467^{c} \times 10^{4} \\
\pm 1286\end{array}$ & $\begin{array}{c}13.13^{\mathrm{a}} \times 10^{4} \\
\pm 3055\end{array}$ & $\begin{array}{l}12.4 \\
78 \%\end{array}$ & $\begin{array}{c}185.53^{\mathrm{d}} \\
\pm .03\end{array}$ \\
\hline $\begin{array}{l}\text { Dicalzoruil } \\
\text { sporulated }\end{array}$ & $\begin{array}{c}286.8 \\
\pm 13.42\end{array}$ & $\begin{array}{c}437.8^{\mathrm{c}} \pm \\
20.12\end{array}$ & $\begin{array}{c}151^{\mathrm{d}} \\
\pm 8.14862\end{array}$ & 111.84 & 100 & $\begin{array}{c}0.3^{\mathrm{a}} \\
\pm 0.47\end{array}$ & $92.1 \%$ & $\begin{array}{c}0.64^{b} \times 10^{4} \\
\pm 100\end{array}$ & $\begin{array}{c}2.27^{\circ} \times 10^{4} \\
\pm 1222\end{array}$ & $\begin{array}{c}8.6^{\mathrm{a}} \times 10^{4} \\
\pm 4000\end{array}$ & $\begin{array}{l}13.1 \\
76 \%\end{array}$ & $\begin{array}{c}198.37^{\mathrm{e}} \\
\pm .46\end{array}$ \\
\hline $\begin{array}{l}\text { Commercial } \\
\text { vaccine }\end{array}$ & $\begin{array}{c}291.4 \\
\pm 27.06\end{array}$ & $\begin{array}{l}375.3^{b} \\
\pm 24\end{array}$ & $\begin{array}{c}85.6^{\mathrm{b}} \\
\pm 14.91606\end{array}$ & 61.156 & 100 & $\begin{array}{l}3.6^{c} \\
\pm 0.67\end{array}$ & $12.5 \%$ & $\begin{array}{c}0.66^{b} \times 10^{4} \\
\pm 100\end{array}$ & $\begin{array}{c}15.79^{\mathrm{b}} \times 10^{4} \\
\pm 3559\end{array}$ & $\begin{array}{c}20.5^{b} \times 10^{6} \\
\pm 3272\end{array}$ & $\begin{array}{l}91.7 \\
69 \%\end{array}$ & $\begin{array}{l}65.89^{b} \\
\pm .65\end{array}$ \\
\hline $\begin{array}{l}\text { Immunized by } \\
\text { un treated } \\
\text { oocyst }\end{array}$ & $292.1 \pm 14$ & $\begin{array}{c}418.6^{c} \pm \\
40.18\end{array}$ & $\begin{aligned} & 126.2^{c} \\
\pm & 28.7549\end{aligned}$ & 92 & 100 & $\begin{array}{c}0.7^{\mathrm{b}} \\
\pm 0.92\end{array}$ & $81.58 \%$ & $\begin{array}{c}2.55^{\mathrm{d}} \times 10^{4} \\
\pm 500\end{array}$ & $\begin{array}{l}2.13^{c} \times 10^{4} \\
\quad \pm 611\end{array}$ & $\begin{array}{c}7.33^{\mathrm{a}} \times 10^{4} \\
\pm 3055\end{array}$ & $\begin{array}{c}12.4 \\
\%\end{array}$ & $\begin{array}{c}178.90^{\circ} \\
\pm .11\end{array}$ \\
\hline $\begin{array}{c}\text { Control } \\
\text { infected un } \\
\text { immunization }\end{array}$ & $\begin{array}{c}281.4 \\
\pm 16.55\end{array}$ & $\begin{array}{c}308.2^{\mathrm{a}} \pm \\
9.028\end{array}$ & $\begin{array}{c}26.8^{\mathrm{a}} \\
\pm \\
8.283853\end{array}$ & 20.23 & 100 & $\begin{array}{l}3.8^{c} \\
\pm 0.41\end{array}$ & $0 \%$ & $.0000^{\mathrm{a}}$ & $\begin{array}{c}17.2033^{\mathrm{a}} \times 10^{4} \\
\quad \pm 3272\end{array}$ & $\begin{array}{c}80.20^{c} \times 10^{6} \\
\pm 529150\end{array}$ & $\begin{array}{c}100 \\
\%\end{array}$ & $\begin{array}{c}16.43^{\mathrm{a}} \\
\pm .00\end{array}$ \\
\hline $\begin{array}{l}\text { Control un } \\
\text { infected un } \\
\text { immunized }\end{array}$ & $\begin{array}{c}292.1 \\
\pm 21.24\end{array}$ & $\begin{array}{c}457.4^{c} \pm \\
20.3\end{array}$ & $\begin{aligned} & 165.3^{\mathrm{e}} \\
\pm & 6.945022\end{aligned}$ & 120.23 & 100 & $0.0^{\mathrm{3}}$ & $100 \%$ & & $0^{d} 0$ & $0^{c}$ & $0 \%$ & $\begin{array}{c}220.23^{f} \\
\pm .00\end{array}$ \\
\hline
\end{tabular}

a, b, c, d, e, f Means in the same column with different superscripts are significantly different $(p<0.05)$.

\section{DISCUSSION}

Eimeria infection occurs when a susceptible chicken ingests a sporulated oocyst from its environment, the sporulated oocyst contains four sporocysts, each sporocyst contains two sporozoites. The sporozoites are released by mechanical and biochemical action in the digestive tract of the chicken (Reid, 1978). The liberated sporozoites invade epithelial cells in a specific zone of the intestine or ceca depending on the species involved (Conway and Mckenzie, 2007). So some recent studies directed on working on both unsporulated and sporulated oocyst to prevent or decrease the infection as studies of Fatemi et al. (2015) and Zaman et al. (2015) who evaluate the inhibition efficacy of herbal extracts on the sporulation process of Eimeria species. Beside the studies of Khalafalla et al. (2011) and Alnassan et al. (2015), who studied the efficacy of some herbal extract as curcumin and allicin on the viability, reproductivity and virulence of E. tenella sporozoites. Additionally to the invitro study of Thabet et al. (2015)who recorded the inhibitory effect of some anticoccidials as ionophors and toltrazuril on $E$. tenella sporozoites.

This work was a complementary part for an in vitro study conducted to evaluate the attenuating activity of diclazuril on Eimeria species unsporulated and sporulated oocysts through treatment of them by these substances, which proved their efficacy in inhibition of Eimeria with high concentration over than $50 \%$, while the $20 \%$ concentration not affect the sporulation but causes some morphological deformities and oocyst wall deterioration that may affect the oocyst virulence through passage of these substances to the formed sporocysts and sporozoites (our un published data in press). The evaluation of this study was based on some anticoccidialindices (Survival rate, lesion value, oocyst value and relative weight gain) and protection against challenge (Ma et al., 2011).

The results illustrated that, the post immunization bloody diarrhea scores, oocyst shedding and lesion score were significant lower in commercial vaccine and diclazuriltreated groups than the immunized by un treated oocyst group, this may referred to the attenuating activity of diclazuril treatment. Diclazuril belongs to the triazine class of compounds (Haberkorn and Stoltefuss, 1987), it has cidal effect against both asexual and sexual stages of E. tenella, the late schizont stages of E.necatrix and $E$. acervulina, the gametocytes of E.brunetti, and the zygote of E. maxima and caused complete disruption of oocyst wall formation in all fertilized macrogamonts resulted in necrosis of the developing oocyst (Conway and Mckenzie, 2007). While the commercial vaccine group by Coccivac D vaccine showed low oocyst shedding and normal or mild lesion may due to it contains mixtures of wild type strains of Eimeria species designed to provide the chicken with immunity without any pathogenic effects (Dalloul and Lillehoj, 2005). While the increased hemorrhagic diarrhea, cecal lesions and inflammatory reactions in the infected by untreated oocyst group may be caused by the invasion and intracellular development stages of Eimeria protozoan in the gut are associated with the induction of local inflammatory response, also avian coccidiosis, several pro inflammatory including tumor necrosis factor- $\alpha$, IL- $1 \beta$,IL- 6 , and IL- 8 and T cell helper type 1 cytokines and chemokines were elevated in the chicken gut following infections with E. tenella, E. acervulina, and E. maxima (Hong et al., 2006a). These soluble mediators of inflammation 
have been proposed to be responsible, in part, for intestinal damage during coccidiosis (Hong et al., 2006b). It was suggested more recently that NO resulted from the oxidative stress indused by the Eimeria invasion might promote the development of coccidial lesions (Allen, 1997).

The results of this study revealed that challenging these immunized groups: diclazuril un sporulated, diclazuril sporulated, commercial vaccine and immunized by un treated oocyst group showed no mortality, milder hemorrhages, fewer oocysts per gram of cecum and dropping, and lower lesion scores. In contrast, commercial vaccine group and the control infected un treated group showed severe clinical signs.

There is a direct relationship between the mean of lesion values (cecal values), bloody diarrhea score in feces and in direct relationship with the protection rate. This rule was achieved in all immunized groups, whereas the immunized groups showed significant high protection percentage and reduction in cecal lesion score in compared to commercial vaccine and control infected un immunized groups. This may referred to immunization could induce an immune response that is adequate to enable birds to resist a challenge with virulent parasites (Chapman et al., 2005), primary immunization with E. tenella, leukocytes infiltrating the lamina propria were predominately macrophages and $\mathrm{T}$ cells, and an increase in the number of CD4+ cells at 2 days post immunization (Vervelde et al., 1996), whereas CD8 + lymphocytes are the necessary effect on cells for immunity to challenge infections (Allen and Fetterer, 2002), thus increased production of IFN-y on days 6 and 7 during primary infection (Lowenthal et al., 1997), which inhibits penetration of epithelial cells by sporozoites of E. tenella in vitro as well as in vivo (Lillehoj and Choi, 1998). Also during Eimeria spp infection in vivo, increased production of IFN-y upregulates production of the pro-inflammatory cytokine IL-ip and the CC chemokine K203 (Laurent et al., 2001).

Regarding the oocyst excretion index at the $7^{\text {th }}$ PC and cecaloocysts count, all immunized groups including; diclazuril un sporulated \& sporulated and immunized by un treated oocyst groups were significantly lower than commercial vaccine and control infected un immunized groups. Decreasing oocyst production PC in immunized groups may be due to increased production of IL-8, IFN-, IL-15, TGF-_4, and IL-1 PI and PC, which increase host protection against coccidiosis and reduce the intracellular development of Eimeria in chicken decreasing fecal oocyst shedding (Zhang et al., 2012). Also secretion of IFN acts through to slow down sporozoite replication in chicken macrophages and fibroblasts, thus decreases fecal oocyst shedding (Yun et al., 2000).
The weight gain index was significantly $(P<0.05)$ higher in all immunized groups and commercial vaccine group than control infected un immunized group. These results may be due to increased level of IFN-y and lymphotactin PI can only enhance body weight gain (Zhang et al., 2012), also IFN-y could be used as a growth promoter, as recombinant chicken IFN-y administered to chickens prior to infection with E. acervulina resulted in enhanced weight gain relative to controls (Lowenthal et al., 1997). In the contrary body weight gain decreased in control infected un immunized group after challenge with Eimeria species oocysts because infected chicks must divert energy from growth to fight the infection, thus disrupting weight gain (Lin et al., 2015).

The results showed significant high anticoccidial indices in all immunized groups than that of than that of commercial vaccine and control un immunized infected group. Whereas, diclazuril sporulated and diclazuril unsporulated groups showed excellent anticoccidial index, while immunized by untreated oocyst and group showed moderate anticoccidial index. On the contrary the commercial vaccine group and control infected un immunized showed anticoccidial inefficacy. The low protection performance of live vaccine (Coccivac D) group (commercial vaccine group) may referred to the rearing system type of the experiment, as we reared the chicks of all groups on a slatted wire cages to avoid exposure of the chicks to the excreted oocysts for correct evaluation of attenuation efficacy. While the production of protective immunity induced by live non attenuated vaccine (Coccivac D) is largely dependent on re infection from the cycling of oocysts resulting from the inoculation dose in the litter system (Dalloul and Lillehoj, 2005). These results go parallel with the results of (Shirley and Bedrnfk, 1997), who reported that the results of field trials with Paracox vaccine contains eight precocious lines (all seven Eimeria species, with two immunologically distinct lines of E. maxima and is formulated to protect chickens against all Eimeria species have shown that control of coccidiosis (as assessed by numbers of oocysts in the litter throughout the rearing period, mean body weights and incidence of gross coccidial lesions or overt disease) has been excellent and Livacox contains precocious lines only of $E$. acervuline and E. maxima, together with an eggadapted line of E. tenella, and is formulated to control the three species generally recognized as being of greatest economic significance in the rearing of broilers (Shirley and Bedrnfk, 1997).

In conclusion; using of $20 \%$ diclazuril treatment in attenuation of Eimeria species mix oocysts is effective to protect chicks against Eimeria challenge. 


\section{REFERENCES}

Allen, P.C. (1997): Nitric oxide production during Eimeria tenella infections in chickens. J. Poult. Sci. 76, 810-813.

Allen, P.C. and Fetterer, R.H. (2002): Recent advances in biology and immunobiology of Eimeria species and in diagnosis and control of infection with these coccidian parasites of poultry. Clin. Microbiol. Rev. 15, 58-65.

Alnassan, A.A.; Thabet, A.; Daugschies, A. and Bangoura, B. (2015): In vitro efficacy of allicin on chicken Eimeria tenella sporozoites. Parasitol. Res. 114,625-630.

Chapman, H.D.; Roberts, B.; Shirley, M.W. and Williams, R.B. (2005): Guidelines for evaluating the efficacy and safety of live anticoccidial vaccines, and obtaining approval for their use in chickens and turkeys. Avian Pathol. 34, 279-290.

Conway, D.P. and McKenzie, M.E. (2007): Poultry Coccidiosis: Diagnostic and Testing Procedures. 3rd ed. Blackwell Publishing. Ames, IA, USA. 164.

Dalloul, R.A. and Lillehoj, H.S. (2005): Recent advances in immuno modulation and vaccination strategies againstcoccidiosis. Avian Dis. 49, 1-8.

$D u, A$. and $H u, S$. (2004): Effects of a herbal complex against Eimeriatenella infection in chickens. J. Vet. Med. B Infect Dis. Vet. Public Health 51, 194-197.

Fatemi, A.; Razavi, M.S.; Asasi, K. and Goudarzi, T.M. (2015): Effects of Artemisia annua extracts on sporulation of Eimeria oocysts. Parasitol. Res. 114, 1207-1211.

Fei, C.; Fan, C.; Zhao, Q.; Lin, Y.; Wang, X.; Zheng, W.; Wang, M.; Zheng, K.; Zheng, L.; Li, T. and Xue, F. (2013): Anticoccidial effects of a novel triazine nitromezuril in broiler chickens. J. Vet. Parasitol. 198, 39-44.

Fetterer, R.H.; Jenkins, M.C.; Miska, K.B. and Barfield, R.C. (2014): Evaluation of an Experimental Irradiated Oocyst Vaccine to Protect Broiler Chicks Against Avian Coccidiosis. Avian Dis. 58: 391-397.

Haberkorn, A. and Stoltefuss, J. (1987): Studies on the activity spectrum of toltrazuril, a new anticoccidial agent. Vet. Med. Rev.1, 22-32.

Hong, Y.H.; Lillehoj, H.S.; Lee, S.H.; Dalloul, R.A. and Lillehoj, E.P. (2006a): Analysis of chicken cytokine and chemokine gene expression following Eimeria acervulina and Eimeria tenella infections. Vet. Immunol. Immunopathol. 114, 209-223.

Hong, Y.H.; Lillehoj, H.S.; Lee, S.H.; Park, D. and Lillehoj, E.P. (2006b): Molecular cloning and characterization of chicken lipopolysaccharide- induced TNF-alpha factor (LITAF). Dev. Comp. Immunol. 30, 919-929.
Johnson, J. and Reid, W.M. (1970): Anticoccidial drugs: Lesion scoring techniques in battery and floor pen experiments with chickens. Exp. Parasitol. 28, 30-36.

Khalafalla, R.E.; Müller, U.; Shahiduzzaman, M.; Dyachenko, V.; Desouky, A.Y.; Alber, G. and Daugschies, A. (2011): Effects of curcumin (diferuloylmethane) on Eimeria tenella sporozoites in vitro. Parasitol. Res. 108, 879886.

Laurent, F.; Mancassola, R.; Lacroix, S.; Menezes, R. and Naciri, M. (2001): Analysis of chicken mucosal immune response to Eimeria tenella and Eimeria maxima infection by quantitative reverse transcroption-PCR. In. f and Immun. 69, 2527-2534.

Li, G.Q.; Kanu, S.; Xiang, F.Y.; Xiao, S.M.; Zhang, L.; Chen, H.W. and Ye, H.J. (2004): Isolation and selection of ionophore-tolerant Eimeria precocious lines: E. tenella, E. maxima, E. acervulina. Vet. Parasitol. 119, 261-276.

Lillehoj, H.S. and Choi, K.D. (1998): Recombinant chicken interferon-gamma-mediated inhibition of Eimeria tenella development in vitro and reduction of oocyst production and body weight loss following Eimeria acervulina challenge infection. Avian Dis. 42, 307-314.

Lin, Z.; Shi, Y.; Deng, B.; Mao, X.; Yu, D. and Li, W. (2015): Protective immunity against Eimeria tenella infection in chickens following oral immunization with Bacillus subtilis expressing Eimeria tenella 3-1E protein. Parasitol. Res. 114, 3229-3236.

Lowenthal, J.W.; York, J.J.; O'Neil, T.E.; Rhodes, S.; Prowse, S.J.; Strom, D.G. and Digby, M.R. (1997): In vivoeffects of chicken interferongamma during infection with Eimeria. J. Interferon Cytokine Res.17, 551-558.

Ma, D.; Ma, C.; Pan, L.; Li, G.; Yang, J.; Hong, J. and Cai, H. (2011): Vaccination of chickens with DNA vaccine encoding Eimeria acervulina 3-1E and chicken IL-15 offers protection against homologous challenge. Exp. Parasitol. 127, 208-214.

Morris, G.M. and Gasser, R.B. (2006): Biotechnological advances in the diagnosis of avian coccidiosis and the analysis of genetic variation in Eimeria. Biotechnol. Adv. 24, 590-603.

Pinard, V.D.; Laan, M.H.; Monvoisin, J.L.; Pery, P.; Hamet, N. and Thomas, M. (1998): Comparison of Outbred Lines of Chickens for Resistance to Experimental Infection with Coccidiosis (Eimeria tenella). In: Breeding and Genetics. Poult. Sci. 77, 185-191.

Reid, W.M. (1978): Coccidiosis. In Diseases of Poultry, 7th ed., ed. Hofstad, M. S., Calnek, B.W., Helmboldt, C. F., Reid, W. M., Yoder, H. W., Jr. 784-815. Ames, IA: Iowa State Univ. Press. 
Reid, W.M. and Long, P.L. (1979): A diagnostic chart for nine species of fowl coccidia. Georgia Univ. Res. Rep. 335.

Shirley, M.W. and Bedrnik, P. (1997): Live attenuated vaccines against avian coccidiosis: Success with precocious and egg-adapted lines of Eimeria. Parasitol. Today 13, 481- 484.

Singh, G.J.P. and Gill, S.S. (1976): Activity of amprolium against different of Eimeria Necatrix infection and effect of medication on development of immunity. Rev. Parasitol. 37, 63-70.

Thabet, A.; Alnassan, A.A.; Daugschies, A. and Bangoura, B. (2015): Combination of cell culture and qPCR to assess the efficacy of different anticoccidials on Eimeria tenella sporozoites. Parasitol. Res. 114, 2155-2163.

Vervelde, L.; Vermeulen, A.N.; Jeurissen, S.H.M. (1996): In situ characterization of leucocyte subpopulations after infection with
Eimeriatenella in chickens. Parasite Immunol. 18, 247-256.

Wang, X.; Wu, L.; Gao, Y.; Zhang, Y.; Weng, Y.B. and Lin, R.Q. (2017): Evaluation of the protective effect of pVAX-EtMIC3recombined plasmid against E. tenella in chicken Parasitol Res. 116, 1023-1028.

Yun, C.H.; Lillehoj, H.S. and Lillehoj, E.P. (2000): Intestinal immune responses to coccidiosis. Dev. Comp. Immunol., 24, 303-324.

Zaman, A.M.; Iqbal, Z.; Abbas, Z.R. and Ul-Haque, E.S. (2015): In vitro Efficacy of Herbal Extracts against Eimeria tenella. Int. J. of Agri. \& Biol. 17, 848-850.

Zhang, L.; Ma, L.; Liu, R.; Zhang, Y.; Zhang, S.; Hu, C.; Song, M.; Cai, J. and Wang, M. (2012): Eimeria tenella heat shock protein 70 enhances protection of recombinant microneme protein MIC2 subunit antigen vaccination against $E$. tenella challenge. Vet. Parasitol. 188, 239-246.

\section{استخدام الدايكلازوريل في إضعاف فصائل الايميريا لإستحاث المناعة لوقاية الكتاكيت البياضة ضد الكوكسيديا

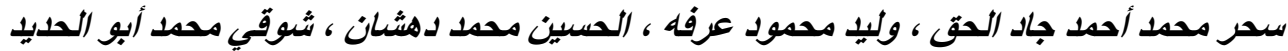

Email:wmarafa@yahoo.com Assiut University web-site: www.aun.edu.eg

أجريت هذه الدر اسة لتقييم قدرة المعالجة بالدايكلازوريل على إضعاف خليط من الطور الجرثومي المتحوصل لطفيل الآيميريا أثناء

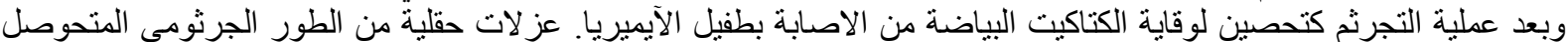

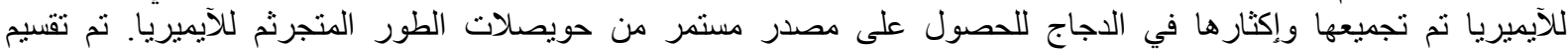

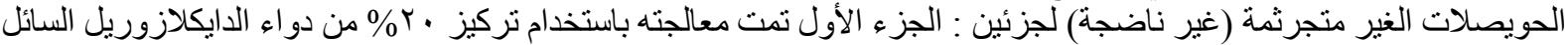

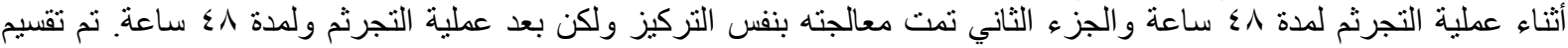

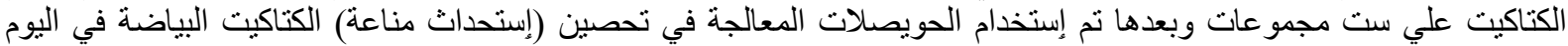

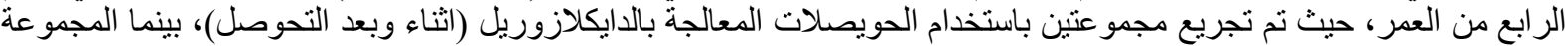

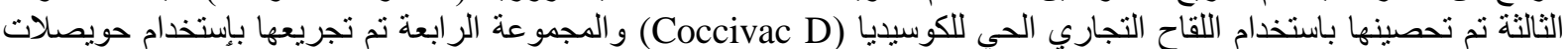

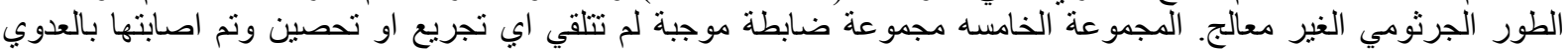

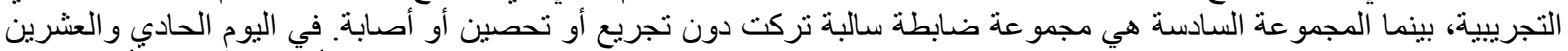

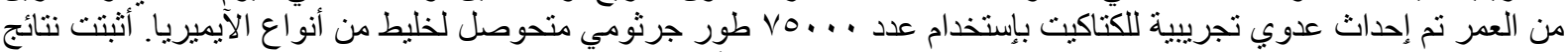

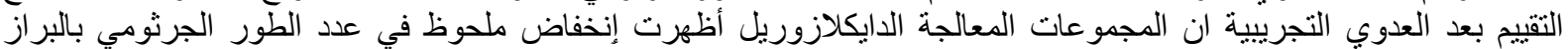

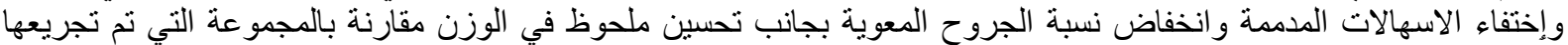

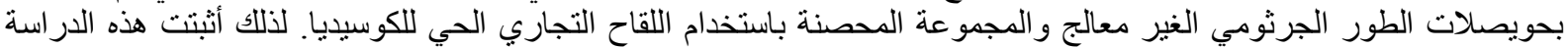
فاعلية المعالجة بالدايكلازوريل في إضعاف حويصلات اليكات الآيميريا المختلفة لإستحداث مناعي وقائي ملحوظ ضد العدوي بالآيميريا في 